\title{
The study of surface processes under electrochemical control in the presence of inertial cavitation.
}

\author{
Peter R. Birkin ${ }^{\mathrm{a}}$, Douglas Offin ${ }^{\mathrm{a}}$ and Timothy G. Leighton ${ }^{\mathrm{b}}$ \\ ${ }^{\mathrm{a} C}$ Chemistry Department and ${ }^{\mathrm{b}}$ ISVR \\ University of Southampton \\ Southampton \\ Highfield \\ SO17 1BJ \\ Email: prb2@soton.ac.uk
}

Tel: 02380594172

Fax: 02380593781

\section{Abstract}

In some circumstances the erosive effects of inertial (transient) cavitation have been usefully employed in the acceleration of chemical processes that are dependent on surface reactions. However, in other situations the erosion of materials can be detrimental. For example erosion/corrosion phenomena have been well documented. It will be demonstrated here that the employment of inertial cavitation can be beneficial to the study of surface processes and indeed has a number of advantages. These include rapid erosion and the removal of small quantities of the surface. To highlight these effects high temporal resolution of the re-oxidation transients 
produced from a passivated microelectrode placed within a cavitation cloud will be reported. These will be compared to the multi bubble sonoluminescence (MBSL) output of the cell.

Keywords: cavitation, erosion, corrosion, microelectrode, MBSL. 


\section{Introduction}

The study of the process termed 'corrosion' is driven by the immense industrial impact of this phenomenon. Corrosion itself can be defined as the reaction of a surface with components within the local environment [1]. Not surprisingly, the study of the formation of oxide layers on metal surfaces is of prime importance to the understanding, prevention and control of this unwanted phenomenon. As part of the investigation of corrosion, the kinetics of the formation of a oxide layer has been well documented in the scientific literature $[2,[3,[4,[5,[6]$. In most cases the kinetics of the oxide film re-formation have been studied (by monitoring the current flowing at the interface under electrochemical control) after erosion of the original oxide has been achieved using a mechanical technique. However there is an inherent limitation with mechanical erosion. This is due to the finite time required to expose the fresh surface, compared to the re-oxidation kinetics of the surface. Alternate methods (such as fracture techniques) have overcome this problem. However, difficulties have been encountered as the result of the often relatively high surface areas exposed. Due to the facile nature of the surface passivation, a relatively high subsequent current has been observed $[7,[8,[9]$. Consequently great care is needed to avoid unwanted distortion through either instrumentation limitations or non-Faradaic contributions. It is clear that a reduction in the area eroded and an increase in the speed of the erosion process would be beneficial to the study of passivation layers on electrode surfaces. One possible solution to this problem is the employment of inertial (transient) cavitation produced by power ultrasound [10].

Inertial cavitation is characterised by the rapid expansion and subsequent collapse of a bubble or void within a liquid [11]. The collapse phase of the cycle has been studied extensively. The collapse results in rebound shock waves emitted into 
the liquid (which may act collectively to erode a surface); or, depending on the proximity of the interface, the bubble may collapse asymmetrically to form a highspeed liquid microjet. In one study, Philip and Lauterborn studied the erosion of a solid surface placed below a large cavitation bubble generated by a laser discharge [12]. They showed that a complex erosion pattern could be detected on the surface of the metal employed. This erosion pattern was determined by optical microscopy and was dependant on the position of the interface with respect to the bubble origin. Birkin et al. have also demonstrated that the erosion of an electrode surface by single inertial cavitation events can be detected using a passivated $\mathrm{Pb}$ microelectrode [10]. In this case a $125 \mu \mathrm{m}$ diameter $\mathrm{Pb}$ electrode was passivated in a sulphate media. Erosion of this 'soft' passivating layer was detected as transient oxidation currents caused by the surface re-oxidation of the exposed $\mathrm{Pb}$. This procedure may be extended to passivated oxide covered surfaces. Figure 1 shows the sequence of events and associated timescales in the erosion/corrosion of a passivated electrode. The cavitation bubble, generated by power ultrasound, collapses under appropriate physical conditions and removes some of the surface of the solid/liquid interface. The spontaneous re-oxidation of the exposed surface is monitored as a current time transient. The advantages of this procedure for the study of passivation kinetics are that the cavitation erosion event occurs over microsecond time scales. This is fast compared to electrochemical events, which are limited by the RC time constant associated with the exposed surface in association with the electrochemical cell over these time scales. Hence the erosion mechanism is over before useful electrochemical data is gathered. In addition a second advantage of this procedure is that relatively small surface areas are removed per cavitation event. One estimation, from the passivated $\mathrm{Pb}$ experiments, of $\sim 100 \mu \mathrm{m}^{2}$ per event has been reported. This compares 
to $2000 \mu \mathrm{m}^{2}$ for fracture events. Under these circumstances, distortion to the current time transients recorded will be less severe in comparison. Finally many events can be generated in a short period of time. The preliminary results of this approach will now be detailed. 


\section{Experimental}

The experimental arrangement has been detailed previously [13]. However, modification of the apparatus allowed XY motion of the microelectrode with respect to the tip with a resolution of $10 \mu \mathrm{m}$. Electrochemical data was captured on a PC through an ADC card (Talismann Electronics, Computer Boards PCI-DAS 4020/12) and software written in-house [14].

Ultrasound and cavitation were generated by means of a Grundig Digimess FG 100 function generator, Brüel \& Kjær Type 2713 power amplifier and ultrasonic transducer fitted with a $3 \mathrm{~mm}$ diameter titanium tip (Adaptive Biosystems). The function generator was interfaced with a PC using software written in-house, allowing the frequency, input voltage and duration of the ultrasound to be controlled accurately.

Microelectrodes were fabricated by sealing type 302 stainless steel wire (74\% $\mathrm{Fe}, 18 \% \mathrm{Cr}, 8 \% \mathrm{Ni}, 25 \mu \mathrm{m}$ diameter, Goodfellow) in soda glass in the standard way [15]. The face of the electrodes were polished with increasing grades of silicon carbide paper followed by aqueous alumina slurries $(1.0 \mu \mathrm{m}$ and $0.3 \mu \mathrm{m})$ to a mirror finish.

All solutions were made up using water from an USF Elga Purelab Option E10 water purification system (concentrations are given in the appropriate figure legend). Water purified in this manner had a conductivity of below $0.06 \mu \mathrm{S} \mathrm{cm}^{-1}$ and a low organic content $\left(\right.$ TOC $<30 \mathrm{ppb}^{\dagger}$ ). Potassium carbonate (Hogg Laboratory Supplies, 99\%) and sodium nitrate (BDH, AnalaR) were used as supplied. All experiments were performed under aerobic conditions at $25 \pm 1{ }^{\circ} \mathrm{C}$. SEM images were recorded on a Philips XL 30 ESEM.

\footnotetext{
${ }^{\dagger}$ Manufacturer quoted figure.
} 


\section{Results}

In order to ascertain the location in the solution where inertial cavitation exists a number of experiments where performed. Figure 2 shows a cyclic voltammogram of the stainless steel microelectrode in a $\mathrm{K}_{2} \mathrm{CO}_{3}$ media $(\mathrm{pH}=12.3)$. Positive of $\sim-0.55 \mathrm{~V}$ vs. SCE, the surface of the microelectrode is essentially passivated. In all further experiments involving the detection of transient oxidation events, the potential of the microelectrode was held at $+0.25 \mathrm{~V} v s$. SCE. Under these potentiostatic conditions erosion of the passivated surface of the microelectrode will be followed by a spontaneous re-oxidation of the exposed surface back to the passivated state. Hence the detection of inertial cavitation within the liquid above the microelectrode will be expressed as transient oxidation events. In the second experiment, an XY scan was performed at a constant microelectrode to ultrasonic tip distance of $0.6 \mathrm{~mm}(\mathrm{Z})$. The electrode was moved manually in $0.25 \mathrm{~mm}$ steps in a plane below the ultrasonic tip and the current was recorded for 2 seconds in each location (while the electrode was stationary). Figure 3 shows the average current as a function of the XY position of the microelectrode (it should be noted that the zero position of both XY axes are arbitrarily defined). Erosion of the microelectrode, which is accompanied by an increased anodic current, is only observed in a relatively localised space below the centre of the tip of the ultrasonic probe employed. In this experiment the area within which erosion, and hence inertial cavitation, are present extends to a radius of $1.4 \pm$ $0.2 \mathrm{~mm}$ from the centre of the operating ultrasonic tip. In this zone, inertial cavitation can be detected as a series of transient oxidation events. Outside of this area no detectible events where recorded over the time period employed in the experiment ( 2 s). The observation that the area within the liquid where erosion events are detected is smaller than the tip of the ultrasonic probe is consistent with the shape of the sound 
field generated by the ultrasonic probe employed. Further discussion of this point is beyond the scope of this paper and is reported elsewhere [14].

Figure 4 shows a complementary experiment designed to detect inertial cavitation within the liquid between the tip and the microelectrode. In this experiment the MBSL output of the cell was recorded with a light sensitive CCD camera. Figure 4 (a) shows an image recorded under normal light conditions, while figure 4 (b) shows an image recorded in a dark room with the ultrasonic source operating. The white area in figure 4 (b) represents a region of the liquid that is emitting light through MBSL. Figure 4 shows that the region in the liquid that emits light (and is henceforth assumed to contain inertial cavitation) is located close to the tip of the ultrasonic source. This is again consistent with the sound field employed. Figure 4 (b) also shows that at an axial distance of $0.6 \mathrm{~mm}$ from the tip of the ultrasonic horn (the separation at which figure 3 was recorded), light emission can be detected up to $0.7 \pm$ $0.1 \mathrm{~mm}$ from the central axis of the horn in the XY plane. This agrees favourably with the location of inertial cavitation activity obtained from the XY scan shown in figure 3 .

Once the centre of maximum erosion had been found within the solution, the microelectrode can be positioned within this zone to employ inertial cavitation as an erosion tool. Figure 5 shows the results from an experiment where the microelectrode was positioned centrally under the ultrasonic horn with a $0.3 \mathrm{~mm}$ electrode to tip separation. At this distance, the microelectrode is well within the zone expected for inertial cavitation (as shown in figures 2 and 4). This close distance also ensures that any minor misalignment of the microelectrode with respect to the tip is insignificant in terms of employing inertial cavitation as an erosion tool. Figure 5 shows the current recorded in the presence of ultrasound as a function of time. A series of 
transient oxidation currents can be observed. It is assumed that these correspond to individual erosion events on the surface of the microelectrode. This is a reasonable assumption given the small size of the electrode employed (25 $\mu \mathrm{m}$ diameter) compared to the maximum radius of the cavitation bubbles. Numerical solutions of the RPNNP equation under conditions similar to those used here predict a value for the maximum radius of the order of $100-150 \mu \mathrm{m}$ depending on the initial bubble size. This implies that prior to any event that induces a re-passivation transient, the electrode is essentially shielded by the collapsing bubble. Nevertheless, it has also been proposed that multiple cavitation bubble collapses can occur which could potentially cause erosion of a surface [16]. However, the experimental data contained in this paper does not allow the actual mechanism of erosion to be ascertained at this time. In any case the physical erosion process is rapid and occurs prior to the electrochemical signal. Hence the exact mechanism, for the study of corrosion transients, is not of primary importance.

Clearly the individual current time transients are of differing height. High sampling rate experiments ( $1 \mathrm{MHz}$, not shown) also confirmed the presence of a range of current time transient sizes. This range of event size is expected if the production of inertial cavitation events occurs randomly throughout the solution in front of the microelectrode. In essence the microelectrode can be thought of as a target. Events directly above the stainless steel electrode will erode the greatest area and hence generate the largest event. However, inertial cavitation at the edge of the microdisc will remove less and subsequently produce a smaller oxidation transient. The degree of surface erosion is also highly dependent on the distance of the cavitation event from the surface of the electrode. In addition to the spatial considerations outlined above, a range of bubble sizes is expected, which would result in a distribution in the 
amount of material eroded by each cavitation event. However, it should be noted that the maximum erosion event is $\sim 500 \mathrm{nA}$, three orders of magnitude smaller than the mA events produced by other erosion/fracture techniques [6, [9]. This should ensure that non-Faradaic effects are minimised. Figure 5 also shows that a significant number of oxidation transients $(>10)$ can be detected in a short period of time (100 $\mathrm{ms})$.

It is possible to estimate the amount of material removed by a cavitation event through simple Faradaic relationships. In order for this to be possible it is necessary to consider the structure of the oxide film. Films grown potentiostatically under conditions similar to those used in this work have been studied using a variety of surface techniques $[17,[18,[19]$. It has been shown that the passive film formed under potential control in alkaline solution on 304 stainless steel consists of $\mathrm{Cr}_{2} \mathrm{O}_{3}$, iron oxide species and hydrated iron species. The exact composition and thickness is dependent on the potential under which the film is grown. However, in all cases there is an inner Cr-rich layer followed by a region consisting mainly of iron oxide species and, close to the surface, a layer of hydrated iron species. Under the conditions used here $(+0.25 \mathrm{~V}$ vs. SCE) the total film thickness is expected to be of the order of $3 \mathrm{~nm}$ [17]. Of this, the Cr-rich section is approximately $1.3 \mathrm{~nm}$ thick, the iron oxide region is of the order of $0.7 \mathrm{~nm}$ thick and the outer hydrated region is $1 \mathrm{~nm}$ thick. Although it is known that at this potential the iron present in the film exists in both $2+$ and $3+$ oxidation states, the amount of iron with a valancy of 2 is relatively small and will be neglected in the calculation. The composition of the film is summarised in table 1 . The total charge passed during a repassivation event consists of contributions from three oxidative processes and can be written as:

$$
Q_{T}=3 F\left(m_{\mathrm{FeOOH}}+2 m_{\mathrm{Fe}_{2} \mathrm{O}_{3}}+2 m_{\mathrm{Cr}_{2} \mathrm{O}_{3}}\right)
$$


where, $F$ is Faradays constant, and $m_{x}$ is the number of moles of each species formed in the reaction. This equation can be used in conjunction with the molar ratio of the reaction products to calculate to total amount of material removed by an erosion event. Consider the re-passivation transient marked with an asterisk (*) in Fig. 3. The charge passed during this event (from the initial current rise until the next transient) was $158 \mathrm{pC}$, which would equate to an area of $3 \mu \mathrm{m}^{2}(1.95 \mu \mathrm{m}$ diameter, assuming a circular erosion pit) assuming the film grows to the $3 \mathrm{~nm}$ thickness within this time $(5 \mathrm{~ms})$. However, film thickness measurements are usually recorded over extended periods of time. Hence the estimation of film thickness is likely to be inaccurate. In order to gain a more meaningful estimation extrapolation to longer time periods is necessary. The spectroscopic data concerning the structure of the film pertains to quasi-steady state conditions after a polarisation period of $\sim 2$ hours. An extrapolation was performed by firstly constructing a double logarithmic plot, which was linear with a gradient of -0.9 . This is consistent with the surface passivating according to high field kinetics and allowed the data to be extrapolated to a time of 7200 s. Over this period a total of $1590 \mathrm{pC}$ would be passed, which equates to an exposed area of $30 \mu \mathrm{m}^{2}(6.18 \mu \mathrm{m}$ diameter $)$. It should be noted that this assumes that double layer effects are relatively small compared to the charge consumed in oxide film growth.

In an attempt to further 'calibrate' the erosion events detected with ultrasound a guillotine experiment was performed. In this experiment a $25 \mu \mathrm{m}$ diameter stainless steel microelectrode was fractured in a glass surround under electrochemical control. Figure 6 shows an oxidation transient recorded from such a fracture experiment. The oxidation event is significantly larger than the transients observed in the inertial cavitation experiments. This is as expected as the guillotine experiment theoretically 
exposes the entire $490 \mu \mathrm{m}^{2}$ microelectrode surface at one time. However, the insert in figure 6 shows a SEM picture of a post fracture microelectrode. This clearly shows that the fracture of the microelectrode is not clean and a significant elongation and fracture process has occurred. This significantly increases the fresh area exposed to the solution in the fracture event. In the case shown an area was estimated to be in excess of $3500 \mu \mathrm{m}^{2}$. Under these circumstances it is inappropriate to calculate the surface area exposed by cavitation using this calibration method. Nevertheless it is clear from the size and associated charge of the cavitation induced erosion events shown in figure 5 , that the area eroded per event is significantly smaller that the total area of the microelectrode.

\section{Conclusion}

The development of a technique designed to investigate the formation of oxide films in a cavitation environment has been undertaken. Transient oxidation events have been detected and these indicate where inertial cavitation exists within the solution. The erosion of oxide occurred within defined positions within the solution. This was found to be located close to the tip of the ultrasonic source. This erosion zone was found to coincide with MBSL data recorded under similar conditions. Individual erosion events on a sub millisecond time domain have been recorded. The technique enables a number of erosion events to be recorded in a short period of time (e.g. $>50$ in $0.4 \mathrm{~s}$ ). The erosion area for an individual event was estimated to be of the order of $30 \mu \mathrm{m}^{2}$ based on a simple Faradaic calculation. 
Acknowledgements

We thank the EPSRC for funding a studentship for DGO under research grant GR/N30989/01. 


\section{Figure Legends}

\section{Figure 1}

Diagram illustrating the erosion and subsequent corrosion of a passivated interface by a single cavitation bubble.

\section{Figure 2}

Plot showing a cyclic voltammogram of a stainless steel microelectrode $(25 \mu \mathrm{m}$ diameter) in $0.5 \mathrm{~mol} \mathrm{dm}^{-3} \mathrm{~K}_{2} \mathrm{CO}_{3}$. The sweep rate was $10 \mathrm{mV} \mathrm{s}^{-1}$.

\section{Figure 3}

Plot showing the erosion/corrosion signal as a function of $\mathrm{XY}$ position at a constant $\mathrm{Z}$ displacement for a $25 \mu \mathrm{m}$ diameter stainless steel microelectrode. The solution contained $0.5 \mathrm{~mol} \mathrm{dm}{ }^{-3} \mathrm{~K}_{2} \mathrm{CO}_{3}$. The electrode to tip separation was $0.6 \mathrm{~mm}$ and the potential was held at $+0.25 \mathrm{~V} v$ s. SCE. Legend indicates average current (recorded over $2 \mathrm{~s}$ ) in $\mathrm{nA}$. The circle indicates the relative size of the ultrasonic tip employed.

\section{Figure 4}

(a) Image showing an ultrasonic horn $(\mathrm{H})$ positioned above a microelectrode $(\mathrm{M})$ taken in the light. The scale bar represents $1.5 \mathrm{~mm}$. (b) Image showing the MBSL output of an operating ultrasonic horn positioned above a microelectrode. The position of the horn $(\mathrm{H})$ and microelectrode $(\mathrm{M})$ are indicated with dotted lines. Solution contained $0.5 \mathrm{~mol} \mathrm{dm}{ }^{-3} \mathrm{~K}_{2} \mathrm{CO}_{3}$. The exposure time was $10 \mathrm{~min}$. 


\section{Figure 5}

Plot showing the current recorded as a function of time for a stainless steel microelectrode $(25 \mu \mathrm{m}$ diameter) exposed to inertial cavitation. The tip/electrode distance was $0.3 \mathrm{~mm}$ and the potential was held at $+0.25 \mathrm{~V}$ vs. SCE. Solution contained $0.5 \mathrm{~mol} \mathrm{dm}{ }^{-3} \mathrm{~K}_{2} \mathrm{CO}_{3}$. Data sampling rate $20 \mathrm{kHz}$.

\section{Figure 6}

Plot showing the current as a function of time for a guillotine experiment on a $25 \mu \mathrm{m}$ diameter stainless steel microelectrode sealed in glass. The solution contained 0.5 mol dm $\mathrm{NaNO}_{3}$ and the electrode potential was held at $+0.75 \mathrm{~V} v s$. stainless steel (the guillotine itself). Data sampling rate $25 \mathrm{kHz}$. The inserted image shows a SEM of a microelectrode post-fracture. The scale bar represents $20 \mu \mathrm{m}$.

\section{Table 1}

Table showing the data employed to calculate the area eroded by a single cavitation event. 

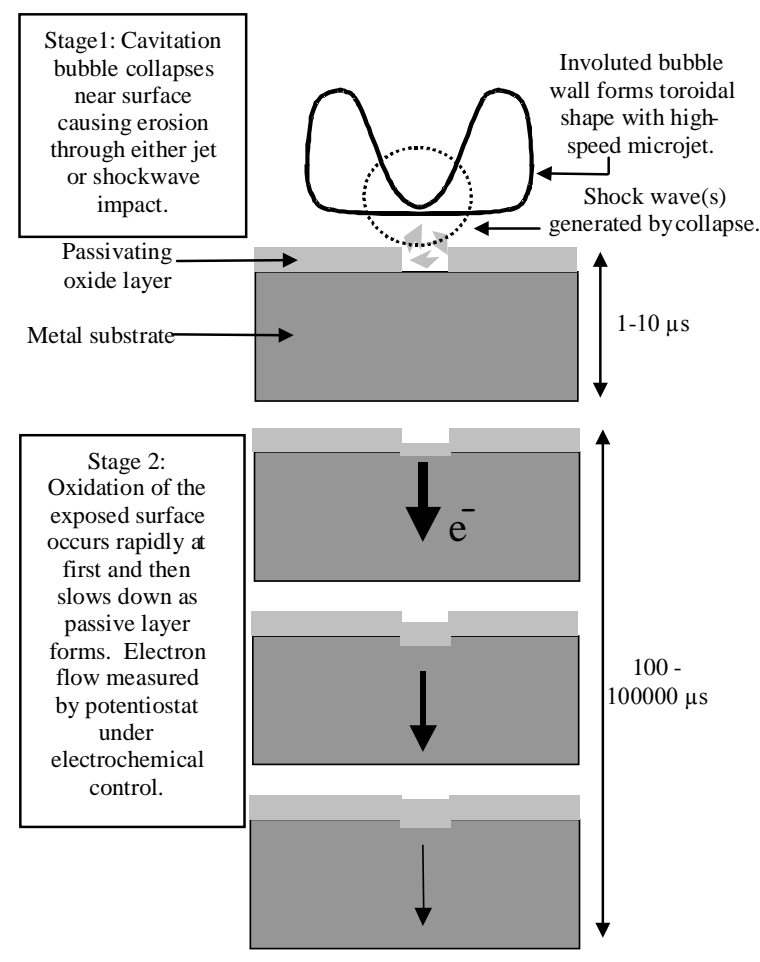

Figure 1 


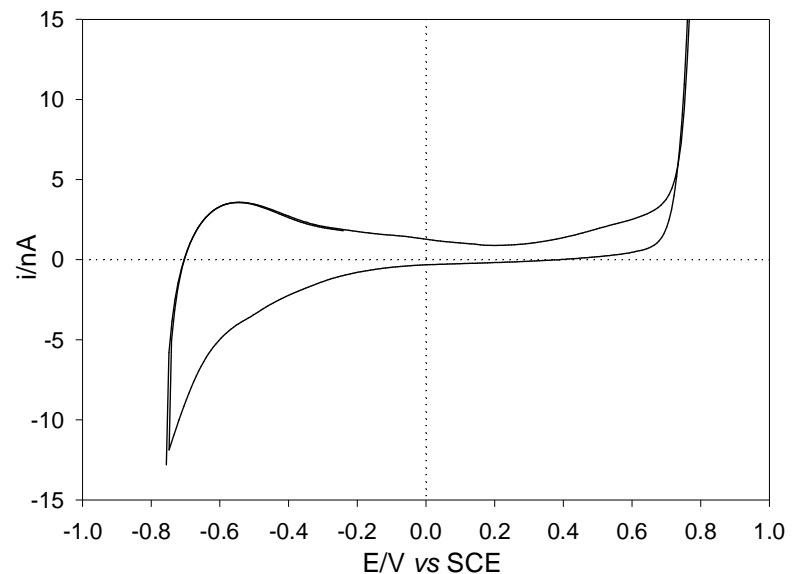

Figure 2 


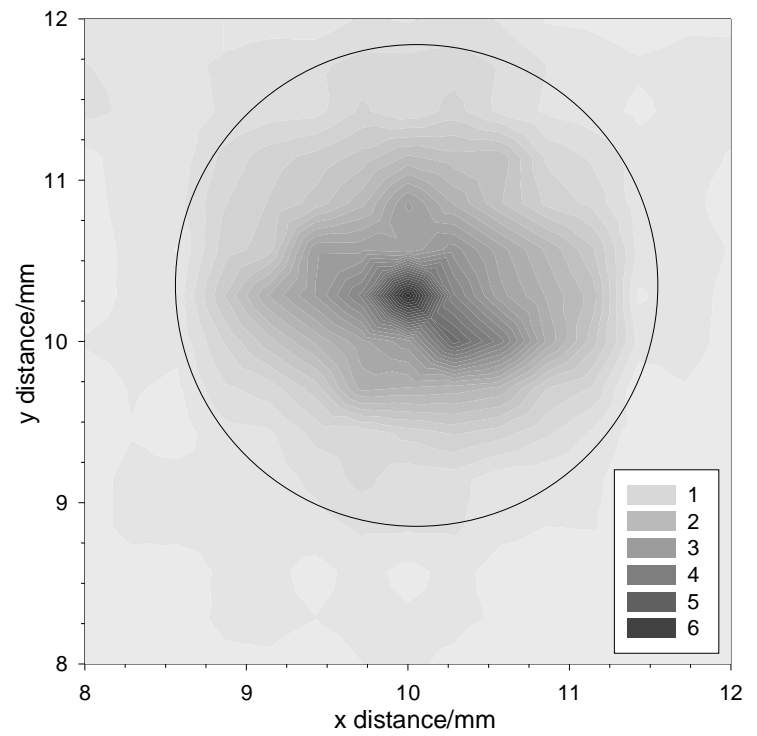

Figure 3 


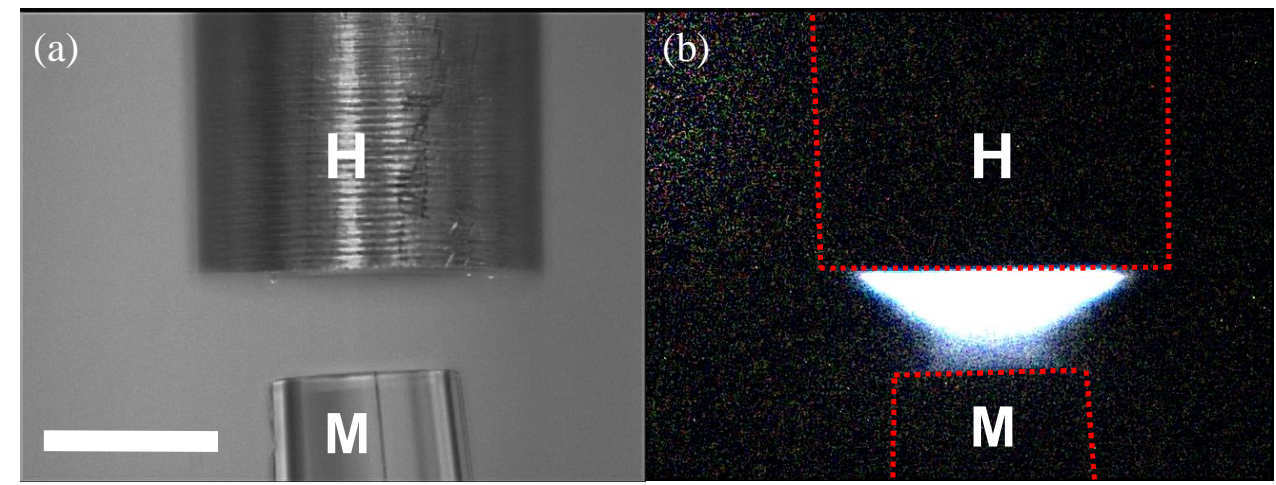

Figure 4 


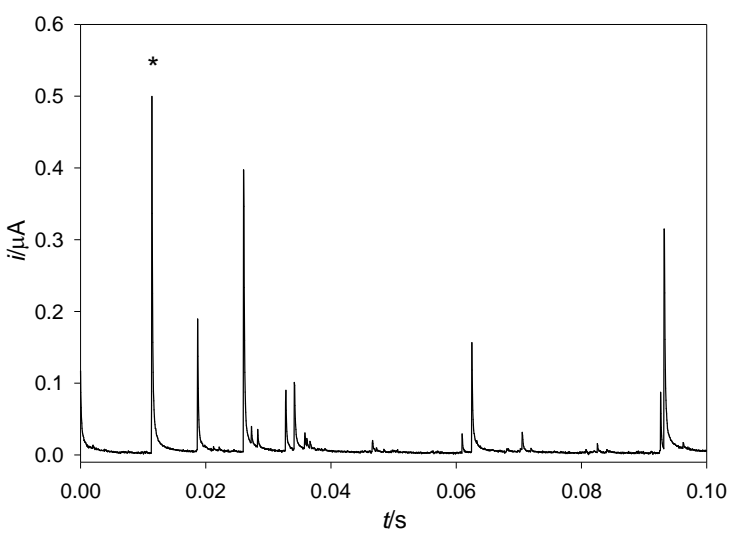

Figure 5 


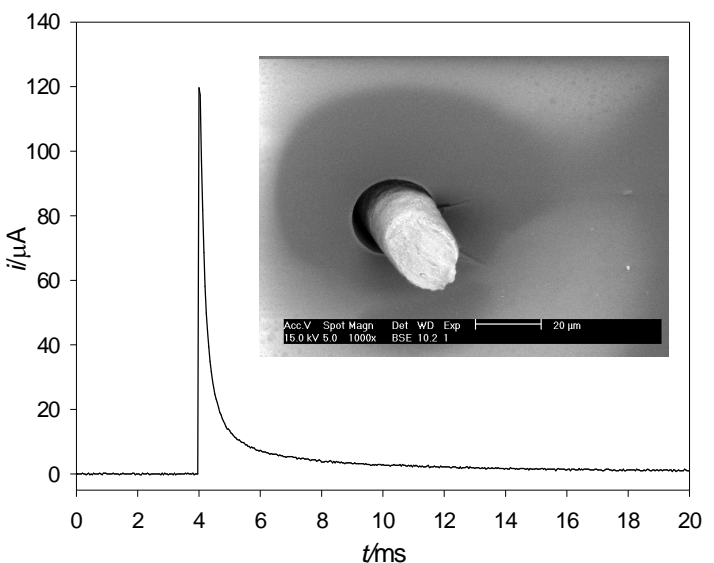

Figure 6 


\begin{tabular}{ccccc}
\hline Species & $\begin{array}{c}\text { Density/ } \\
\mathrm{g} \mathrm{cm}^{-3}\end{array}$ & $\begin{array}{c}\text { Mol. Mass/ } \\
\text { g mol }^{-1}\end{array}$ & $\begin{array}{c}\text { \% by } \\
\text { Volume }\end{array}$ & $\begin{array}{c}\% \text { by } \\
\text { Moles }\end{array}$ \\
\hline $\mathrm{FeOOH}$ & 4.18 & 88.85 & 33.33 & 41.06 \\
$\mathrm{Fe}_{2} \mathrm{O}_{3}$ & 5.24 & 159.69 & 23.33 & 20.05 \\
$\mathrm{Cr}_{2} \mathrm{O}_{3}$ & 5.21 & 151.99 & 43.33 & 38.89 \\
\hline
\end{tabular}

Table 1. 
References

1. D. Pletcher, A first course in electrode processes, The Electrochemical Consultancy, Southampton, 1991, p.274.

2. G. T. Burstein, R. C. Newman, Reactions of scratched copper electrodes in aqueous solutions, Journal of the Electrochemical Society, 128 (1981) 2270.

3. G. T. Burstein, D. H. Davies, The electrochemical behaviour of scratched iron surfaces in aqueous solutions, Journal of the Electrochemical Society, 128 (1981) 33. 4. M. Joseph, D. Klenerman, A second-harmonic generation study of a corrosion inhibitor on a mild steel electrode, Journal of Electroanalytical Chemistry, 340 (1992) 301.

5. G. T. Burstein, A. J. Davenport, The current-time relationship during anodic oxide film growth under high electric field, Journal of the Electrochemical Society, 136 (1989) 936.

6. G. S. Frankel, C. V. Jahnes, V. Brusic, A. J. Davenport, Repassivation transients measured with the breaking-electrode technique on aluminum thin-film samples, Journal of the Electrochemical Society, 142 (1995) 2290.

7. R. Oltra, O. Yavas, Study of localized pulsed laser depassivation by interferometric probe, Applied Surface Science, 108 (1997) 219.

8. G. T. Burstein, C. Lui, Electrochimica Acta, Time-resolved electrochemical impedance of the guillotined aluminium electrode, 39 (1994) 873.

9. G. S. Frankel, B. M. Bush, C. V. Jahnes, C. E. Farrell, A. J. Davenport, H. S. Issacs, Repassivation transients measured with thin film breaking electrodes, Journal of the Electrochemical Society, 138 (1991) 643.

10. P. R. Birkin, R. O'Connor, C. Rapple, S. Silva-Martinez, Electrochemical measurement of erosion from individual cavitation generated from continuous ultrasound, Journal of the Chemical Society Faraday Transactions, 94 (1998) 3365.

11. T. G. Leighton, The acoustic bubble, Academic Press, London, 1994, 12. A. Philip, W. Lauterborn, Cavitation erosion by single laser-produced bubbles, Journal of Fluid Mechanics, 361 (1998) 75.

13. P. R. Birkin, S. Silva-Martinez, A study of the effect of ultrasound on mass transfer to a microelectrode, Journal of Electroanalytical Chemistry, 416 (1996) 127. 14. P. R. Birkin, D. G. Offin, T. G. Leighton, Experimental and theoretical characterisation of sonochemical cells - part 2 cell disruptors, In preparation, (2003)

15. G. Denuault, Microelectrodes, Chemistry in Industry, 18 (1996) 678.

16. I. Hansson, K. A. Mørch, The dynamics of cavity clusters in ultrasonic (vibratory) cavitation erosion, Journal of Applied Physics, 51 (1980) 4651.

17. G. Lorang, M. Da Cunha Belo, A. M. P. Simões, M. G. S. Ferreira, Chemical composition of passive films on AISI 304 stainless steel, Journal of the Electrochemistry Society, 141 (1994) 3347.

18. P. Schmuki, From Bacon to barriers: A review on the passivity of metals and alloys, Journal of Solid State Electrochemistry, 6 (2002) 145.

19. C.-O. A. Olsson, D. Landolt, Passive films on stainless steels - chemistry, structure and growth, Electrochimica Acta, 48 (2003) 1093. 